\title{
Research on Sliding Mode Control Technology in Chain Tension of Scraper Conveyor of Coal Mine
}

\author{
Shangfu Gong and Na Yang* \\ School of Computer Science and Technology, Xi'An University of Science and \\ Technology, Xi'An 710054, China \\ gongsf@xust.edu.cn, *yangnalys@foxmail.com
}

\begin{abstract}
Because that the scraper conveyor chain tension control has characteristics of randomness, nonlinear and time-variation in the coal mine, the paper put forward using sliding mode control technology to make tension control system have better dynamic performances. This method utilizes combined reaching law that combining exponential reaching law and variable rate reaching law to design switching function, then calculates the law of sliding mode control for chain tension control system, in order to constantly make tension move along the prescriptive state trajectory. The results of simulation show that, chain tension control with sliding mode control method has better dynamic characteristics of smaller overshoot, no oscillation and stronger robustness.
\end{abstract}

Keywords: Scraper conveyor; Tension control; sliding mode control

\section{Introduction}

Scraper conveyor is mechanical transportation equipment with chain-type traction. Not only it is an important device of underground fully mechanized mining face, but also its operation condition largely has effects on production efficiency of the mining face [1]. The carrying capacity of scraper conveyor changes dynamically, the load bearing has a characteristic of unbalanced impact, also running resistance and chain tension both have characteristics of randomness, nonlinear and time-variation. The above points lead to phenomena of looser chains or tighter chains in the process of running. Looser chains could damage the mesh of sprockets and chains, resulting in the shock, vibration or dropping of chains; tighter chains could increase the running resistance of conveyor scraper, bringing larger power consumption and excessively making elements abrasions [2]. In order to prevent occurrences of these phenomena, the chain tension must be made automatically adjustment in real time for adapting to the changes of loads.

Actually the changes of loads constantly result to giving a precise value for tension control value difficultly, so numerous scholars have made research for this problem [3]. Fangwei XIE designed a strategy of fuzzy immune PID control that realizes soft start with sigmoid curve. This strategy makes output speed follow designated speed commendably, but has minor wave of control [4]. Lihong DONG designed a tension control system of scraper conveyor based on Kalman filter. This control method adopts linear recursion algorithm to handle observation value and gets real-time optimal estimating values of system signals. It can eliminate effectives of disturbances and measuring noises, but the tension respond has oscillations with small range in the beginning stage [5]. Junxia WANG utilized fuzzy adaptive PID technique which adjusts the parameters of proportion, integral, differential on line to achieve tension control. This technique has higher response speed, but its overshoot of tracking respond is larger and some certain oscillations exist in the initial stage [6].

Trough analyzing advantages and weaknesses of the above literatures for the control of scraper conveyor chain tension, aiming at varieties of nonlinear, time-varying and 
stochastic interferences existing in the control of chain tension of scraper conveyor, the sliding mode control (SMC) technique is introduced into the control of chain tension to acquire control results with smaller overshoot and no-oscillation. Sliding mode control is a special kind of nonlinear control technique, whose nonlinear performance is characterized by discontinuous control [7]. The difference between sliding mode control strategy and other control methods is that, system "structure" of sliding mode control is not fixed and can be changed on purpose according to the current states of system in the dynamic process, forcing the system running in accordance with the desired state trajectory of "sliding mode". So the sliding mode control is widely applied in kinds of time-varying, nonlinear and uncertain systems [8]. Experimental results show that, utilizing sliding mode control technique to achieve chain tension control has advantages of fast response, strong robustness, smaller overshoot and no-oscillation. This method can adapt to the characteristics and requirements of scraper conveyor chain tension control in the complex working environment, and provide reliable theoretical foundations and experimental bases.

\section{The Principle of Automatic Chain Tension Control}

The principle of automatic chain tension control of scraper conveyor is shown in Figure 1. Through changing the distance of two sprockets, to realize the compensation of tension changes caused by loads leading to elastic elongation (or contraction) of chains, and restrict the minimum tension value within a suitable range. Sensors in the system are used to detect tension signals $T_{A}$ and $T_{B}$ which are output values of system. Through analysis and processing of signals, the detected $T_{A}$ and $T_{B}$ which detected by signal comparator $I$ compare with the expected value for getting the deviation signal $\Delta T_{A}$ and $\Delta T_{B}$. Then, signal comparator $I I$ is adopted to judge that whether the $\Delta T_{A}$ and $\Delta T_{B}$ exceed the setting error value $[\Delta T]$. Finally the system outputs the trigger signals $e_{A}$ and $e_{B}$ which are signal generators of controlling hydraulic cylinders $A$ and $B$ to control the expansion of cylinders in the machine tails, so as to achieve the purpose of automatically adjusting the tightness of chains [9].

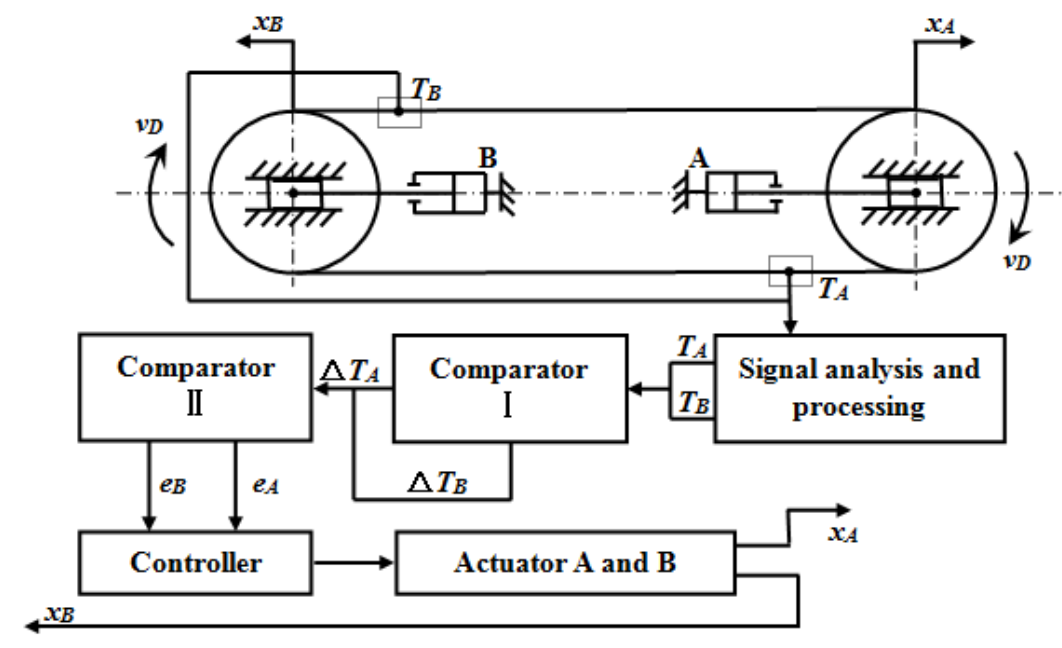

Figure 1. The Principle of Automatic Chain Tension Control of Scraper Conveyor 


\section{Mathematical Model of Chain Tension Control}

Through simplifying dynamic model of the scraper conveyor with chain tension hydraulic automatic control system, the mathematical model equation is obtained as follows [10].

$U_{r}$ is the voltage signal corresponding to the desired tension value, $U f$ is the feedback voltage signal corresponding to the measured tension, $U_{e}=U_{r}-U_{f} ; U_{f}=K_{f} T_{A}, K f$ is the gain of sensor; $T_{A}$ is the tension of measuring point. When $T_{A}=\left[T_{A}\right]$, corresponding to $U_{f}=U_{r 0}$, where $\left[T_{A}\right]$ is the expected tension value of measuring point. Regardless of the dynamic characteristics of electronic amplifiers, the output current is $\Delta I_{i}=K_{a} U_{e}, K_{a}$ is the gain of amplifier.

In consideration of the flow transfer function of electro-hydraulic proportional valve and liquid increment of entering hydraulic cylinder, then without consideration for the friction of mass $m_{A}$, the transfer function between tension $T_{A}$ and $U_{e}$ can be derived as

$$
T_{A}(s)=\frac{K_{p v} K_{a} H_{p v}(s) A_{c}\left(K_{n l}+C_{n l} s\right)}{A_{c}^{2} s+\left(m_{A} s^{2}+C s+K\right)\left(\beta_{e c} s-C_{l p}\right)} U_{e}(s),
$$

where $K_{p v}$ is the gain of proportional valve; $H_{p v}(s)$ is the transfer function of proportional valve when $K_{p v}=1 ; A_{c}$ is the importing oil cavities area, $A_{c}=2 \pi r^{2}, r$ is the inside radius of cylinder; $K=K_{l}+K_{n l}, K_{l}$ and $K_{n} l$ respectively are the equivalent stiffness coefficient of on-load side chains and no-load side chains; $C=C_{l}+C_{n l}, C_{l}$ and $C_{n l}$ are the equivalent damping coefficient of on-load side chains and no-load side chains; $\beta_{e c}$ is the effective volume expansion coefficient of internal pipeline of hydraulic cylinder; $C_{l p}$ is the leakage coefficient of hydraulic cylinder. The block diagram of chain tension control system of scraper conveyor is shown in Figure 2.

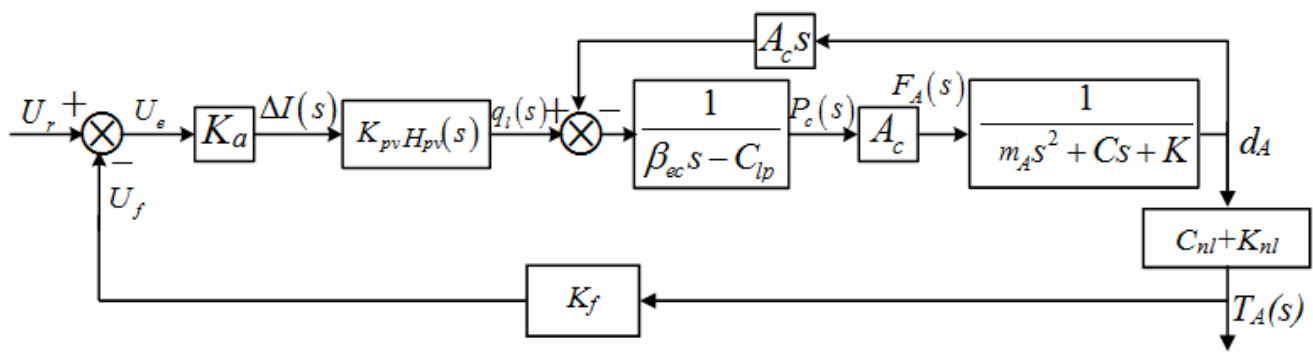

Figure 2. Block Diagram of Scraper Chain Tension Control System

\section{Chain Tension Control based on Sliding Mode Control}

In practical circumstances, chain tension control system of scraper conveyor has nonlinear and time-varying characteristics. The principle diagram of utilizing sliding mode control for chain tension control is shown in Figure 3.

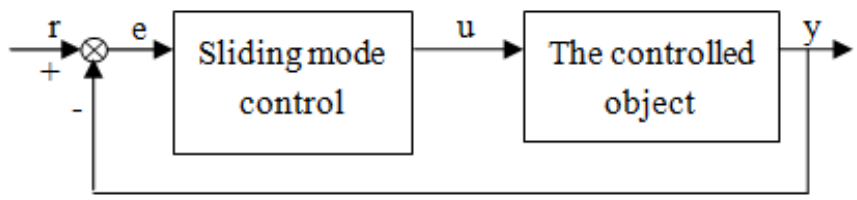

Figure 3. The Principle Diagram of Chain Tension Control Based on Sliding Mode Control 
Sliding mode control has a property of discontinuity, which can force the system to do an up-and-down movement which has small amplitude and high frequency along a prescriptive state trajectory under a certain characteristic, so that names "sliding mode" movement. The sliding mode can be designed and has nothing to do with the parameters of system, in this way, the system with sliding mode movement has greater robustness [11].

However, the essentially discontinuous switching characteristic of sliding mode control could result in chattering of system.

In order to weaken the chattering and improve the performance of system, this paper utilizes the method of combined reaching law that combining exponential reaching law and variable rate reaching law to design sliding mode controller for acheiving chain tension control.

Set the discrete state equation of chain tension control system of scraper conveyor as

$$
x(k+1)=W x(k)+N u(k),
$$

where $x(k)=\left[x_{1}(k), x_{2}(k)\right], x$ is the system state of chain tension; $W, N$ are coefficient matrices; $u$ is controlled variable of chain tension.

Set the command signal of chain tension control as $r(k)$, its changing rate as $d r(k)$. Take $R=[r(k) ; d r(k)], R_{1}=[r(k+1) ; d r(k+1)]$.

Use the method of linear extrapolation to predict $r(k+1)$ and $d r(k+1)$ as

$$
r(k+1)=2 r(k)-r(k-1), d r(k+1)=2 d r(k)-d r(k-1) .
$$

Set the error signal of chain tension control as $E=R-x(k)$, thus the switching function is

$$
s(k)=C_{e} E=C_{e}(R-x(k)),
$$

where $C_{e}=[c, 1]$. So

$$
\begin{aligned}
s(k+1)=C_{e}\left(R_{1}-x(\right. & (k+1)) \\
& =C_{e}\left(R_{1}-W x(k)-N u(k)\right) \\
& =C_{e} R_{1}-C_{e} M x(k)-C_{e} N u(k) .
\end{aligned}
$$

Then, the control law of chain tension control is obtained as

$$
u(k)=\left(C_{e} N\right)^{-1}\left(C_{e} R_{1}-C_{e} M x(k)-s(k+1)\right) .
$$

1) Exponential reaching law

Adopt exponential reaching law

$$
s(k+1)=s(k)+T(-\varepsilon \operatorname{sgn}(s(k))-q s(k)),
$$

which satisfies the reaching condition of sliding mode [12].

Take the equation of formula (7) into formula (6), the control law of chain tension control based on exponential reaching law is obtained as

$$
u(k)=\left(C_{e} N\right)^{-1}\left(C_{e} R_{1}-C_{e} M x(k)-s(k)-d s(k)\right),
$$

where $d(k)=T(-\varepsilon \operatorname{sgn}(s(k))-q s(k))$.

Among them, reaching speed parameter $q$ mainly affects the dynamic transition process of switching function. The proper adjustment of $q$ can change the reaching speed of arriving the sliding mode surface for system, and can better improve the dynamic qualities of chain tension system. The $q$ is bigger, the speed of reaching the sliding mode surface is faster, especially $q$ is closer to $1 / T$, the faster the system approaches.

Design of sliding surface slope $c$ is to guarantee that the sliding mode motion is asymptotically stable and has a higher dynamic response speed. The $c$ is higher, the speed of response in sliding mode motion is faster. 
Therefore, the increase of $c$ and $q$ can increase the speed of system. But oversize parameters may lead larger control output. In the actual control, it often causes the chattering of system.

Gain parameter $\varepsilon$ of symbolic function is a main parameter of system to overcome perturbation and external disturbance. $\varepsilon$ is bigger, the ability of overcoming perturbation and external disturbance is stronger. However, the oversize gain will cause increase of system chattering. Generally speaking, the chattering amplitude of system should be proportional to $\varepsilon$.

2) Variable rate reaching law

Adopt exponential reaching law

$$
s(k+1)-s(k)=-\varepsilon T\|x(k)\|_{1}-\operatorname{sgn}(s(k)),
$$

where $\|x(k)\|_{1}=\sum\left|x_{i}(k)\right|$ is the norm of system state. It satisfies the reaching condition of sliding mode [13].

Take the equation of formula (9) into formula (6), the control law of chain tension control based on variable rate reaching law is obtained as

$$
u(k)=\left(C_{e} N\right)^{-1}\left(C_{e} R_{1}-C_{e} M x(k)-s(k)-d s(k)\right),
$$

where $d(k)=-\varepsilon T\|x(k)\|_{1}-\operatorname{sgn}(s(k))$.

Variable rate reaching law uses control way which all state variables constitute. The approach velocity is $\varepsilon\|x(k)\|_{1}$ which proportional to $\|x(k)\|_{1}$, and their proportional coefficient is $\varepsilon$. If $\|x(k)\|_{1}$ is too big and $\varepsilon$ is big, the system will have larger chattering when reaches the switching surface; if $\|x(k)\|_{1}$ is too small, the reaching speed will slower and regulation time will longer. Therefore, the appropriate $\varepsilon$ should be chosen.

3) Combined reaching law

For the exponential reaching law, from formula (7) know that, when $s(k)=0^{+}$, $s(k+1)=-\varepsilon T$; when $s(k)=0^{-}, s(k+1)=\varepsilon T$. It indicates that the switch zone of exponential reaching law is a band with width of $2 \varepsilon T$ but without the origin. It shows that the sliding mode function of system switches back and forth between these two values when staying at the steady state.

As for the variable rate reaching law, when $s(k)=0^{+}, s(k+1)=-\varepsilon T\|x(k)\|_{1}$; when $s(k)=0^{-}$, $s(k+1)=\varepsilon T\|x(k)\|_{1}$. Its switching zone is composed by two rays with origin, and places $s=0$ inside. It shows that the system can be stabilized to the origin, and has good steady-state performance when staying at the steady state.

In order to overcome the shortcoming that the swiching zone of exponential reaching law is a band, which finally tends to the origin, rather than becomes a chattering near the origin, and reduce the burden of the controller, this paper eventually adds the variable rate reaching law to the exponential reaching law, forming a sliding mode control method based on the combined reaching law to solve the problem of chain tension control.

The method of adopting the combined reaching law is that, to utilize the formula (8) of the sliding mode control based on exponential reaching law in the early stage of chain tension control; to utilize the formula (10) of the sliding mode control based on variable rate reaching law in the later stage and steady period of chain tension control.

In this way, we can overcome the shortcomings of these two laws, and retain the advantages of them. Thereby the performance of the system can achieve the best.

The tension control law based on the combined reaching law is as follows

$$
u(k)=\left\{\begin{array}{c}
u(k)=\left(C_{e} B\right)^{-1}\left(C_{e} R_{1}-C_{e} A x(k)-s(k)-T(-\varepsilon \operatorname{sgn}(s(k))-q s(k))\right),\|x(k)\|_{1} \geq k_{0} \\
u(k)=\left(C_{e} B\right)^{-1}\left(C_{e} R_{1}-C_{e} A x(k)-s(k)+\varepsilon T\|x(k)\|_{1}+\operatorname{sgn}(s(k)),\|x(k)\|_{1}<k_{0}\right.
\end{array},\right.
$$


where $K_{0}$ is a positive real number.

If $K_{0}$ is chosen too big, it will cover the advantages of the variable rate reaching law; If $K_{0}$ is chosen too small, it may produce larger chattering. Therefore, the value of $K_{0}$ should be chosen based on the actual circumstances.

To utilize the combined control law (11), the performances of system can be enhanced and the stability of system can be improved.

Finally, by using the sliding mode control law $u$ as formula (11) to calculate the specific output value of the sliding mode controller, the practical output value of the controlled object can be obtained. Then making a comparison with the expected value of system, in order to bring the output tension value close to the expected value. In this way, the real-time control of the chain tension based on sliding mode control can be realized with improved control performance.

\section{Simulation Experiment}

According to basic principles of scraper conveyor engineering design, referring to operation parameter manuals and making some proper calculations, the parameters can be got as $K_{a}=0.2(\mathrm{~A} / \mathrm{V}), \quad K_{p v}=1(\mathrm{~m} / \mathrm{A}), \quad A_{c}=0.0226\left(\mathrm{~m}^{2}\right), \quad m_{A}=880(\mathrm{~kg}), \quad \beta_{e c}=8 \times 10^{-7}\left(\mathrm{~m}^{3} /{ }^{\circ} \mathrm{C}\right)$ , $\quad C_{l p}=5 \times 10^{-12}\left(\mathrm{~m}^{5} / \mathrm{N} \cdot \mathrm{s}\right), \quad C_{n l}=2.9(\mathrm{~N} \cdot \mathrm{s} / \mathrm{m}), \quad K_{n l}=0.76 \times 10^{-7}(\mathrm{~N} / \mathrm{m}), \quad C=5.8(\mathrm{~N} \cdot \mathrm{s} / \mathrm{m})$, $K=1.52 \times 10^{-7}(\mathrm{~N} / \mathrm{m}), \quad K_{f}=0.025(\mathrm{~V} / \mathrm{N})$.

By taking each parameter of chain tension control system of scraper conveyor into the block diagram of transfer function that shown in Figure 2, then adjusting the calculated transfer function into the zero-pole form, and taking no account of the poles which have smaller impact on the system performance and the zeros which have larger absolute value [14], the mathematical model of chain tension control system can be simplified into a two-order function as the formula (12), which is the controlled object in this paper.

$$
G_{c o}(s)=\frac{\mathrm{T}_{A}(s)}{U_{r}(s)}=\frac{0.270}{s^{2}+12.528 s}
$$

To express the controlled object of tension control system as the form of state equation: $x(k+1)=W x(k)+N u(k)$,

where $W=\left[\begin{array}{ll}1 & 0.0010 \\ 0 & 0.9997\end{array}\right], \quad N=\left[\begin{array}{l}0.000006 \\ 0.012526\end{array}\right]$.

The performance of tension control based on sliding mode control can be verified by the MATLAB simulation experiment, and this control algorithm is realized by Mfunction.

In the combined reaching law of sliding mode control, the value of $c$ is 8 , the value of $\varepsilon$ is 1 , the value of $q$ is 45 and the value of $K_{0}$ is 0.006 by design principles.

The simulation experiment is mainly making a comparison and an analysis amomg the simulation results of conventional PID control, fuzzy immune PID control and sliding mode control for tension control.

When imposing pretension signal $25 \mathrm{kN}$ on the scraper conveyor chains, the dynamic response curves of simulation output are obtained as shown in Figure 4. 


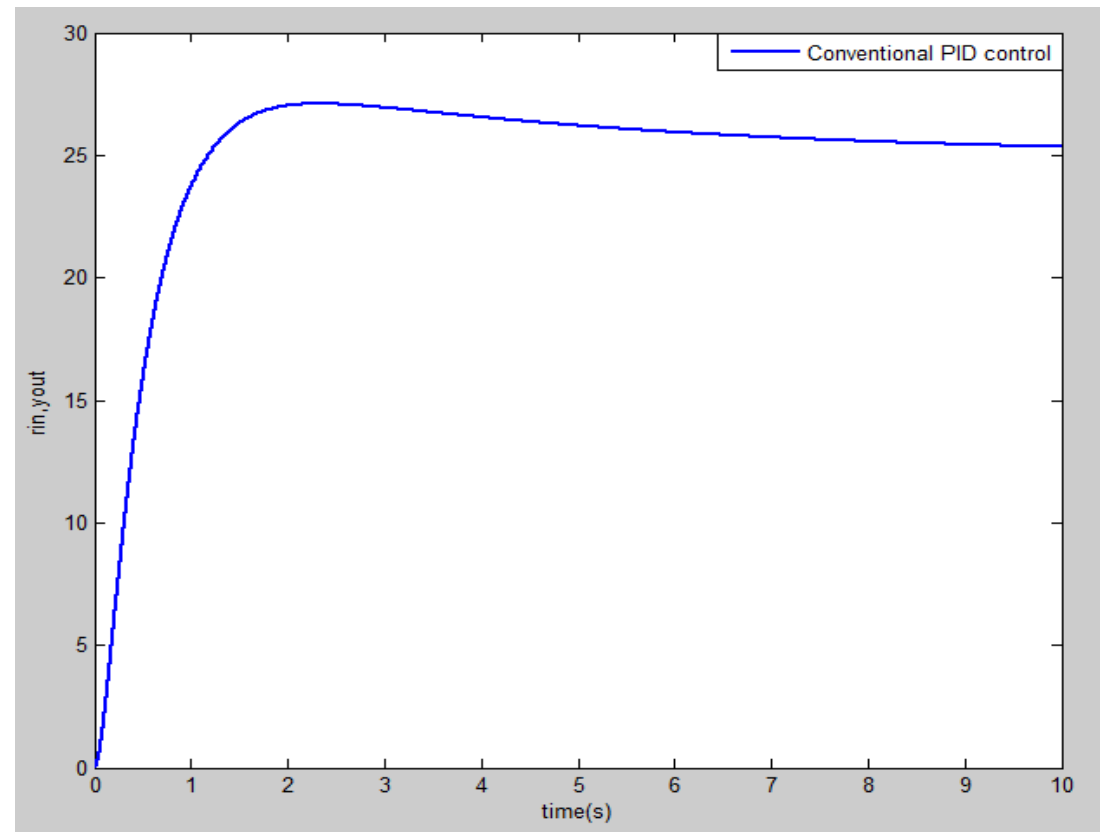

(a) Conventional PID Control

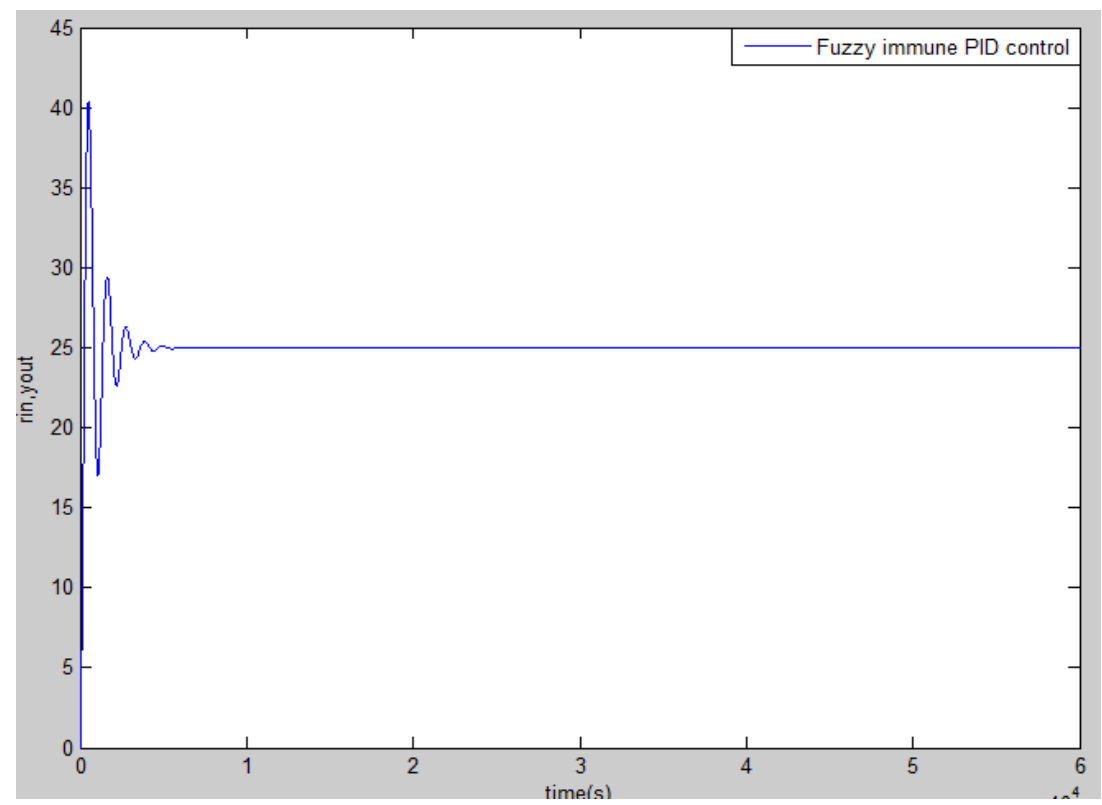

(b) Fuzzy Immune PID Control 


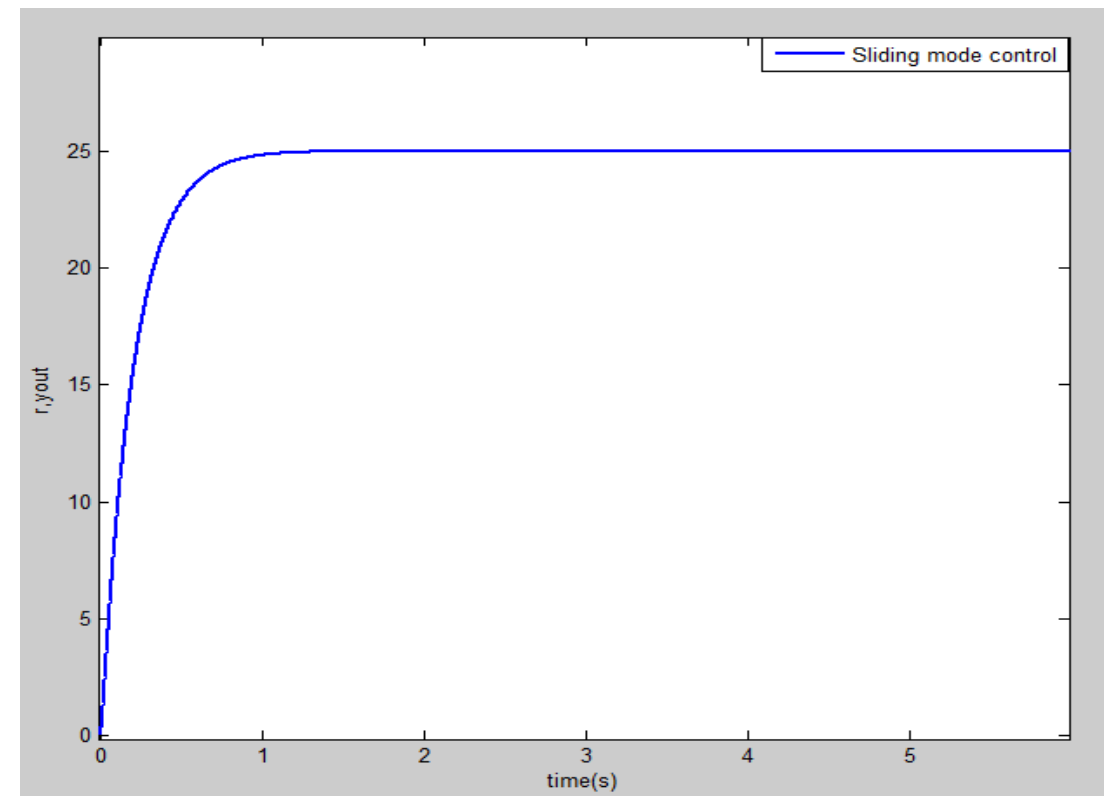

(c) SMC Control

\section{Figure 4. Comparison of the Performances of Dynamic Step Response When Imposing 25kn Loads}

From Figure 4, when the tension control system suffers the pulse load, compared with conventional PID control, the response speed of fuzzy immune PID control is fast, but its overshoot is larger and there exists some oscillations.

At the same time, the sliding mode control has a smaller overshoot and a shorter adjusting time under the pulse load compared with conventional PID control. It is also obvious that the dynamic performances of sliding mode control for scraper conveyor chain tension are far superior and steadier than the fuzzy immune PID control. In a word, sliding mode control can get stable and rapid control results than conventional PID control and fuzzy immune PID control for chain tension control.

When the target value of scraper conveyor chain tension is constant, the controller must be able to keep the chain tension constant under the dynamic disturbance. When the target value of chain tension changes, for example, the pretension needs to be adjusted again if changing the placing length or other parameters, the controller should have an ability to make the chain tension change follow the target value. Therefore, the dynamic tracking performance of controller for the target value requires a consideration.

The dynamic tracking target values of chain tension are in accordance with two deferent signals. One is a square wave signal that has period of $4 \mathrm{~s}$ and amplitude of 2 , the other is a sine wave signal that has period of $2 \mathrm{~s}$ and amplitude of 0.5 .

When the target signal changes in pace with the above two signals, the dynamic tracking performances of conventional PID control, fuzzy immune PID control and sliding mode control are compared as shown in Figure 5, Figure 6 and Figure 7.

Figure 5 shows results of tracking response of conventional PID control for chain tension. Figure 6 shows results of fuzzy immune PID control. Figure 7 shows results of sliding mode control. 


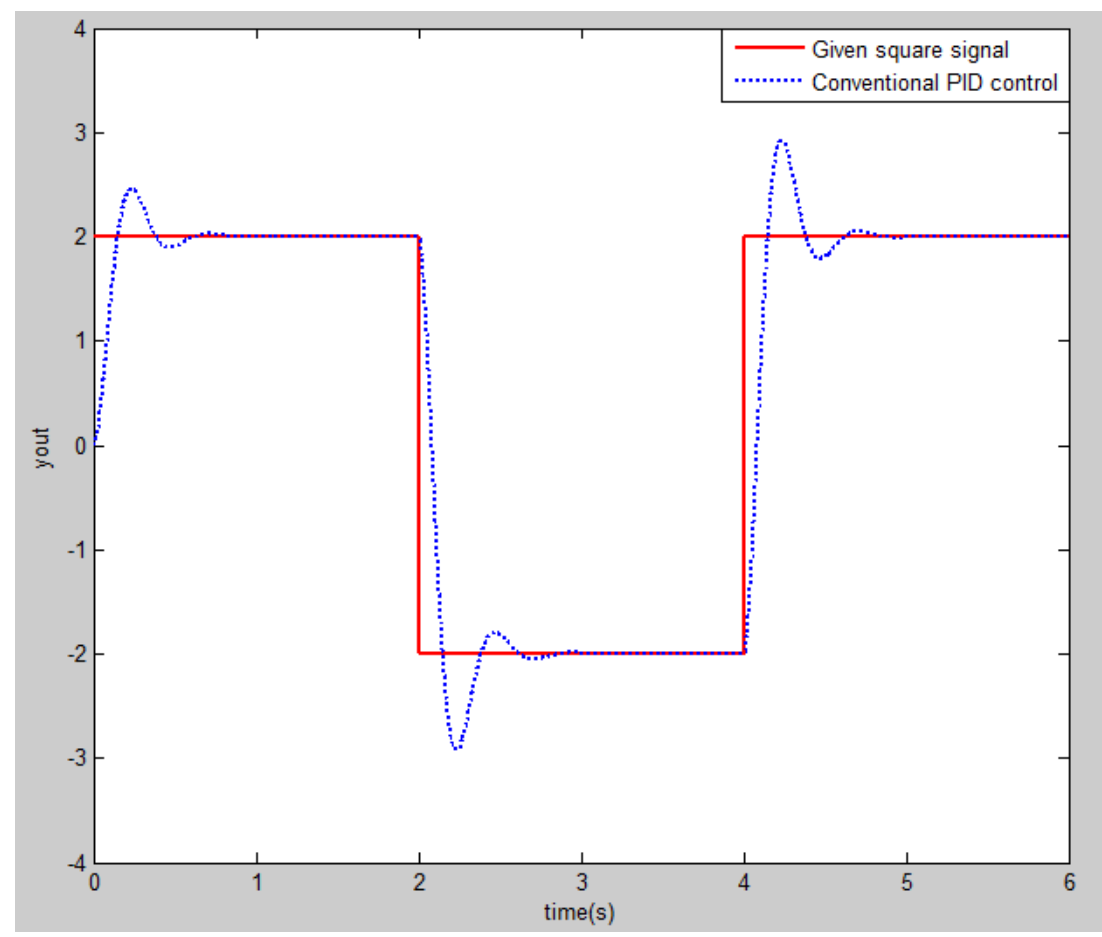

(a) Square Wave Signal

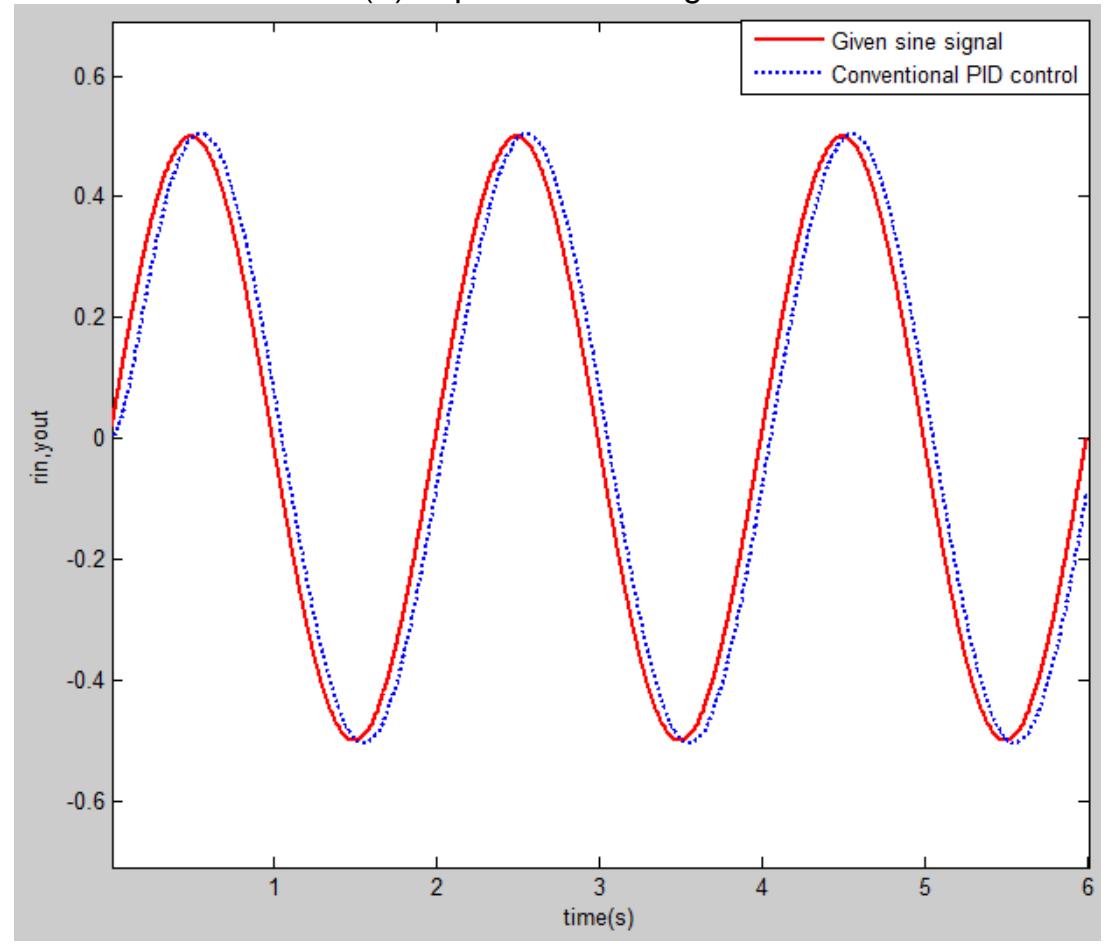

(b) Sine Wave Signal

Figure 5. Tracking Response of Conventional PID Control 


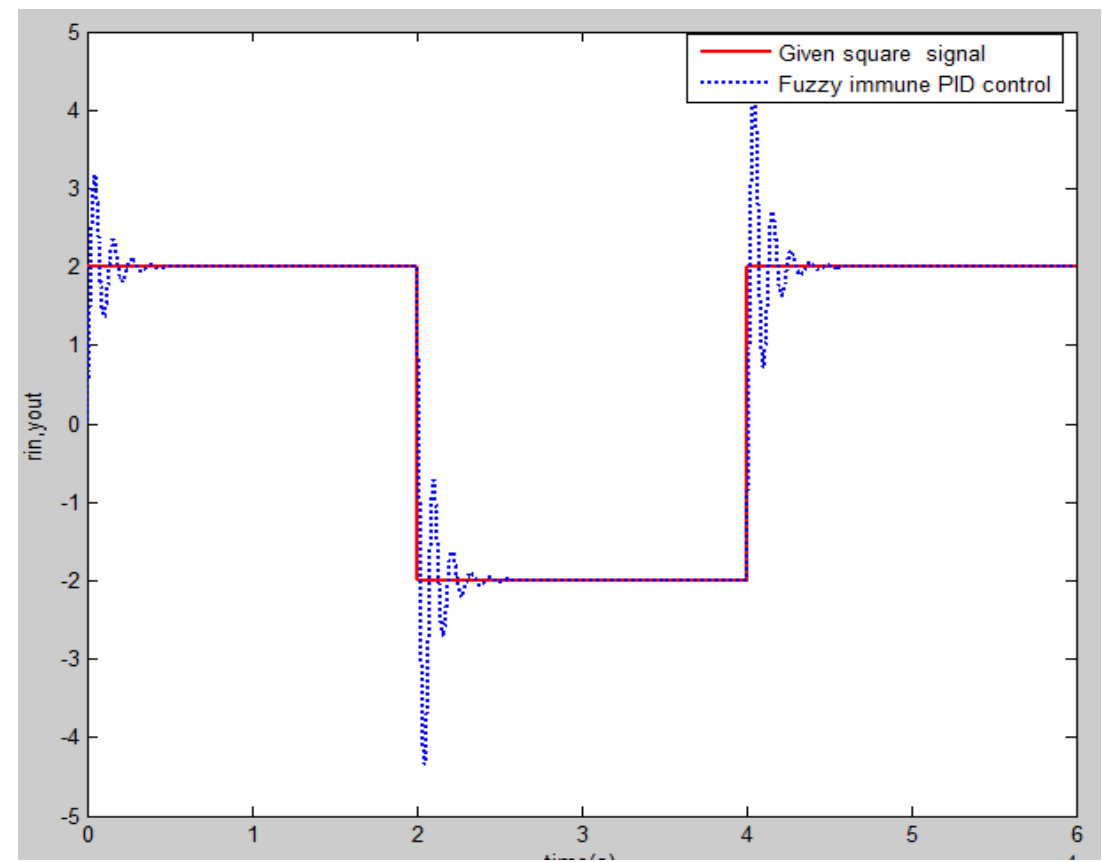

(a) Square Wave Signal

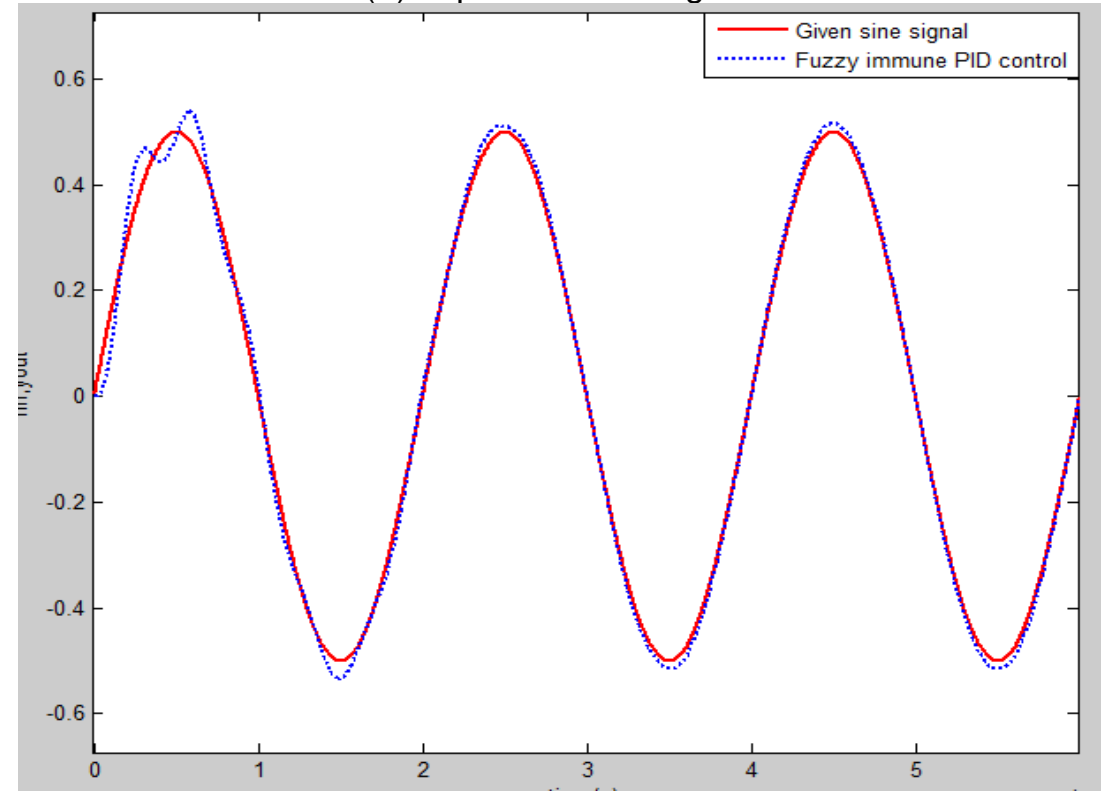

(b) Sine Wave Signal

Figure 6. Tracking Response of Fuzzy Immune PID Control 


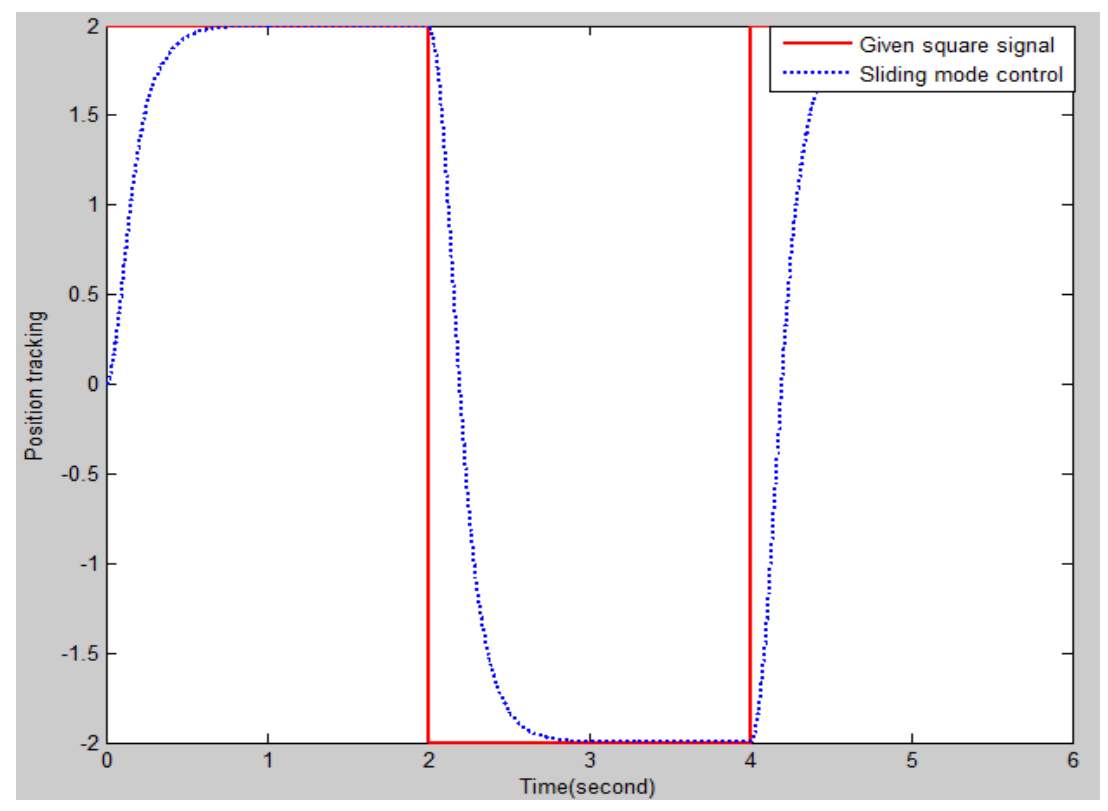

(a) Square Wave Signal

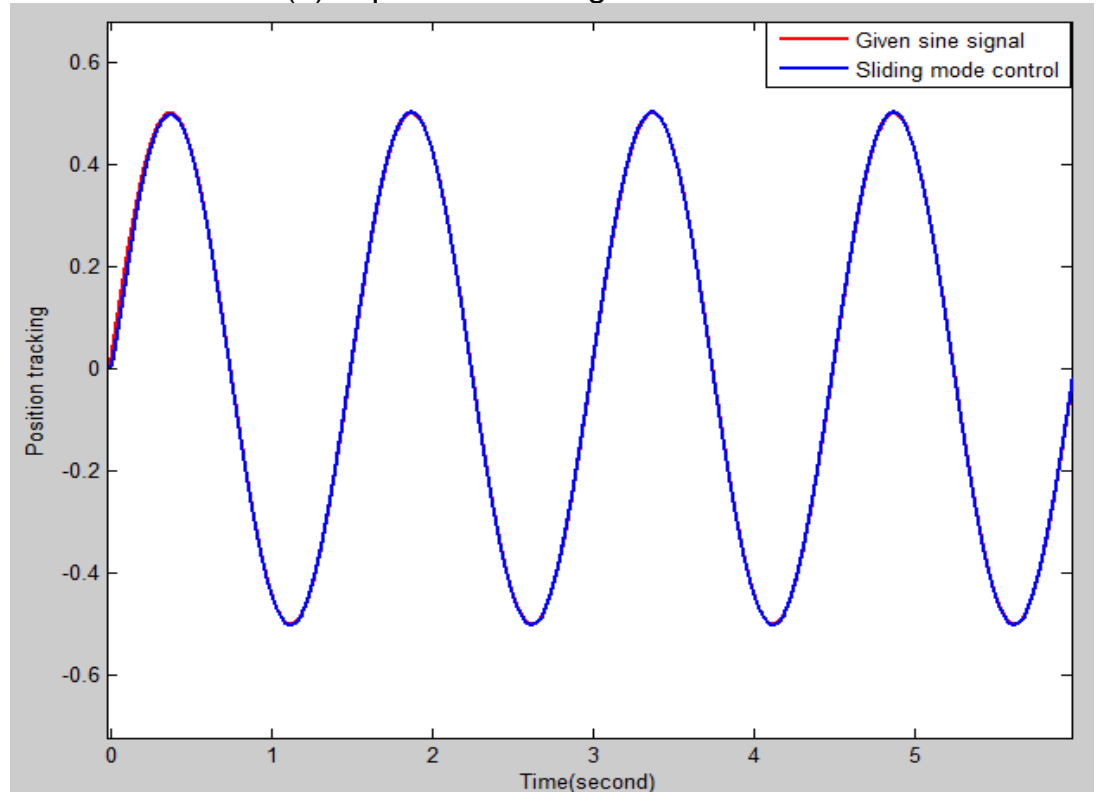

(b) Sine Wave Signal

Figure 7. Tracking Response of Siding Mode Control

For the square wave signal, (a) of Figure 5 indicates that conventional PID control method has a large overshoot and oscillation in the rising edges and the fall edges of the square wave. From (a) of Figure 6, we can know that fuzzy immune PID control has shorter adjusting time to achieve desired value, but it also owns larger overshoot and oscillation in the rising edges and the fall edges of the square wave. However, (a) of Figure 7 shows that sliding mode control has no overshoot and no oscillation, it can realize better dynamic tracking performance for scraper conveyor chain tension control system.

For the sine wave signal, (b) of Figure 5 shows that dynamic tracking performance of conventional PID control method cannot be synchronized with the given sine wave signal. From (b) of Figure 6, it indicates that fuzzy immune PID control can achieve tracking 
most of signals compared with conventional PID control, but it cannot keep accordance with the given sine wave signal in the wave peak and wave valley. However, (b) of Figure 7 shows that the curve of sliding mode control nearly coincides with the given sine wave signal, performing that sliding mode control has a good dynamic tracking performance for scraper conveyor chain tension control system.

To sum up, no matter the chain tension target value of scraper conveyor is a fixed value, or expected chain tension value changes, adopting sliding mode control can realize improved dynamic tension control effects. The proposed control method for tension control has better dynamic characteristics of smaller overshoot, no oscillation and stronger robustness.

\section{Summary}

In order to overcome various effects of stochastic, time-varying and nonlinear disturbance for the dynamic performances of scraper conveyor chain tension control system, the sliding mode control is proposed to solve the control problem of chain tension. This control method makes the system move along the prescriptive state trajectory in a certain characteristic, and combined reaching law can weaken the chattering of sliding mode control. The results of simulations show that, to utilize the method of sliding mode control can not only make the tension control system achieve the dynamic response with faster speed and higher precision, but also make the system has smaller overshoot, no oscillation and stronger robustness. In a word, the proposed method has a great value in the engineering applications of scraper conveyor chain tension control.

\section{References}

[1] C. Zhang, "Dynamic modeling of AFC sprocket transmission system and research of the chains fatigue reliability", Master thesis, China University of Mining and Technology, Beijing, (2012).

[2] F. Yan, "The study on the AFC's chain tension detection control simulate system", Master thesis. Guizhou University, Guiyang, (2009).

[3] J. Liu, "The Mechanical Study of Scraper", Master thesis. Liaoning Technical University, Liaoning, (2005).

[4] F. Xie and Y. Hou, "Fuzzy-immune control strategy of a hydro-viscous soft start device of a belt conveyor", J. Coal Mine Machinery, (2009).

[5] L. Dong, "Tension control system of scraper conveyor based on Kalman filter", J. Computer Engineering \& Science, (2013).

[6] Y. Wang and Z. Wei, "Application study of fuzzy adaptive PID technology in scraper conveyor chain tension control", J. Coal Mine Machinery, (2012).

[7] W. Perruquetti and J.P. Barbot, "Sliding mode control in engineering”, Marel Dekker Inc, New York, (2002).

[8] J. Liu and F. Sun, "Research and development on theory and algorthm of sliding mode control", J. Control Theory \& Applications, (2007).

[9] W. Li, M. Jun and J. Li, "Research on pretension regulating system in scraper conveyor", J. Mining and Processing Equipment, (2009).

[10] J. Mao, D. Zhang and J.-G. Shi, "Simulation research of tension automatic control system of scraper conveyer", J. Journal of System Simulation, (2008).

[11] J. Liu, "MATLAB simulation for sliding mode control", Tsinghua University Press, Beijing, (2005).

[12] Q. Lv, D. Wang and F. Liu, "Discrete-time sliding mode variable structure control based on nonlinear exponential reaching law", J. Journal of Projectiles, (2012).

[13] J. Zhou and H. Jiang, "General variable rate reaching law of discrete-time variable structure control systems", J. Electric Machines and Control, (2005).

[14] G. Obinata and D.Q. Brain, "Model reduction for control system design”, Springer, Berlin, (2001). 


\section{Authors}

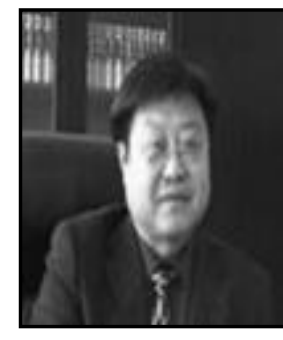

Shangfu Gong, he is a professor in Xi an University of Science and Technology, the main research direction is intelligent monitoring and control system, senior member of Chinese computer institute: 10848 S.

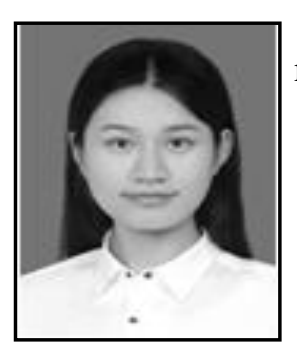

Na Yang, she master in Xi'an University of Science, main research direction is intelligent monitoring and control system. 
International Journal of Control and Automation Vol. 9, No. 11 (2016) 